\title{
PLANT DIVERSITY, SOIL MICROBIAL COMMUNITIES, AND ECOSYSTEM FUNCTION: ARE THERE ANY LINKS?
}

\author{
Donald R. Zak, ${ }^{1,4}$ William E. Holmes, ${ }^{1}$ David C. White, ${ }^{2}$ Aaron D. Peacock, ${ }^{2}$ And David Tilman ${ }^{3}$ \\ ${ }^{1}$ School of Natural Resources and Environment, University of Michigan, Ann Arbor, Michigan 48109-1115 USA \\ ${ }^{2}$ Center for Biomarker Analysis, University of Tennessee, Knoxville, Tennessee 37932 USA \\ ${ }^{3}$ Department of Ecology, Evolution and Behavior, University of Minnesota, St. Paul, Minnesota 55108 USA
}

\begin{abstract}
A current debate in ecology centers on the extent to which ecosystem function depends on biodiversity. Here, we provide evidence from a long-term field manipulation of plant diversity that soil microbial communities, and the key ecosystem processes that they mediate, are significantly altered by plant species richness. After seven years of plant growth, we determined the composition and function of soil microbial communities beneath experimental plant diversity treatments containing 1-16 species. Microbial community biomass, respiration, and fungal abundance significantly increased with greater plant diversity, as did $\mathrm{N}$ mineralization rates. However, changes in microbial community biomass, activity, and composition largely resulted from the higher levels of plant production associated with greater diversity, rather than from plant diversity per se. Nonetheless, greater plant production could not explain more rapid $\mathrm{N}$ mineralization, indicating that plant diversity affected this microbial process, which controls rates of ecosystem $\mathrm{N}$ cycling. Greater $\mathrm{N}$ availability probably contributed to the positive relationship between plant diversity and productivity in the $\mathrm{N}$-limited soils of our experiment, suggesting that plant-microbe interactions in soil are an integral component of plant diversity's influence on ecosystem function.
\end{abstract}

Key words: biodiversity; ecosystem function; gross $N$ immobilization; gross $N$ mineralization; microbial communities; phospholipid fatty acid analysis; plant communities; soil $C$ and $N$ cycling; soil microbes; species richness.

\section{INTRODUCTION}

Human activity has greatly accelerated the rate at which species have disappeared from the Earth (May et al. 1995), and it is likely that the current rate of species loss will increase by an order of magnitude over the next century (Pimm et al. 1995). Although the loss of plant species directly alters the remaining community by lowering its diversity, there is considerable debate as to whether reductions in plant diversity will affect the manner in which terrestrial ecosystems function (Loreau et al. 2001). Some experimental evidence suggests that greater plant species or functional group richness can foster higher rates of net primary productivity (Hector et al. 1999, Tilman et al. 2001), but the mechanisms underlying this response are not well understood, nor are they fully resolved. For example, this positive relationship has been attributed to niche complementarity and facilitation by some (Tilman et al. 1996, Hooper and Vitousek 1998, Caldeira et al. 2001), whereas others have argued that it results from the greater likelihood of a superior competitor occurring in a species-rich experimental plant community (i.e., "sampling effect," sensu Huston 1997). Although more recent analyses indicate that niche complemen-

Manuscript received 18 July 2002; revised 31 October 2002; accepted 8 November 2002; final version received 16 December 2002. Corresponding Editor: J. P. Schimel.

${ }^{4}$ E-mail:drzak@umich.edu tarity can enhance primary productivity in species-rich plant communities (Loreau and Hector 2001, Tilman et al. 2001), it is uncertain whether changes in plant diversity directly influence higher trophic levels that further regulate energy and nutrient flow in terrestrial ecosystems.

Heterotrophic microbial communities inhabiting soil mediate key processes that control ecosystem carbon (C) and nitrogen (N) cycling, and they potentially represent a mechanistic link between plant diversity and ecosystem function. However, few studies have experimentally investigated the influence of plant diversity on soil microorganisms (Bargett and Shine 1999, Wardle et al. 1999, Stephan et al. 2000), yet there are reasons to expect that plant diversity could affect microbial communities and the ecosystem processes they mediate. The availability of growth-limiting resources shapes the composition of biotic communities (Tilman 1982, 1987), and resource availability for soil microbial communities is constrained by organic compounds in dead leaves and roots (i.e., detritus) that can be used to generate cellular energy (Smith and Paul 1990). Because plant species differ in their biochemical composition, changes in plant diversity could alter the production, as well as the range, of organic compounds in detritus that limit, and thus control, the composition and function of heterotrophic microbial communities. We hypothesized that changes in plant diversity will 
TABle 1. Properties of old-field soils that have received experimental plant species richness treatments.

\begin{tabular}{|c|c|c|c|c|c|c|c|c|}
\hline \multirow{2}{*}{$\begin{array}{c}\text { Richness } \\
\text { (no. } \\
\text { species) }\end{array}$} & \multicolumn{2}{|c|}{ Total C (mg C/g) } & \multicolumn{2}{|c|}{ Total N (mg N/g) } & \multicolumn{2}{|c|}{ Soil C:N } & \multicolumn{2}{|c|}{$\mathrm{pH}$} \\
\hline & Mean & $1 \mathrm{SE}$ & Mean & $1 \mathrm{SE}$ & Mean & $1 \mathrm{SE}$ & Mean & $1 \mathrm{SE}$ \\
\hline 1 & $4.22^{\mathrm{a}}$ & 0.173 & $0.34^{\mathrm{a}}$ & 0.015 & $12.0^{\mathrm{a}}$ & 0.15 & $6.09^{\mathrm{a}}$ & 0.017 \\
\hline 2 & $4.60^{\mathrm{a}}$ & 0.229 & $0.38^{\mathrm{a}}$ & 0.017 & $12.3^{\mathrm{ab}}$ & 0.16 & $6.18^{\mathrm{ab}}$ & 0.066 \\
\hline 4 & $4.58^{\mathrm{a}}$ & 0.318 & $0.37^{a}$ & 0.022 & $12.5^{\mathrm{ab}}$ & 0.17 & $6.11^{\mathrm{a}}$ & 0.061 \\
\hline 8 & $4.89^{\mathrm{a}}$ & 0.326 & $0.39^{\mathrm{a}}$ & 0.022 & $12.3^{\mathrm{ab}}$ & 0.16 & $6.02^{\mathrm{a}}$ & 0.056 \\
\hline 16 & $4.77^{a}$ & 0.210 & $0.37^{a}$ & 0.014 & $12.7^{\mathrm{b}}$ & 0.16 & $6.36^{\mathrm{b}}$ & 0.073 \\
\hline
\end{tabular}

Notes: Samples collected in July 2000 were used to characterize soil physical and chemical characteristics. Means in a column with the same letter are not significantly different at $P=$ 0.05 .

modify resource availability for heterotrophic microbial communities in soil, and thus will modify their composition and function. We also hypothesized that changes in microbial community composition and function, in response to altered resource availability, will directly influence rates of soil $\mathrm{C}$ and $\mathrm{N}$ cycling. Our rationale differs from that of a recent theoretical analysis, which predicted that the diversity of organic substrates in detritus would have no effect, or a negative effect, on microbial processes controlling ecosystem-level dynamics (Loreau 2001).

To test these alternatives, we quantified the composition and function of soil microbial communities in a long-term field experiment in which the richness of grassland and savanna plants was manipulated in sandy soil poor in organic matter (Tilman et al. 1996, 2001). We reasoned that the effect of plant species richness on heterotrophic microbial communities would be most apparent in soil containing relatively low initial quantities of growth-limiting organic substrates (i.e., organic matter). In our experiment, plant productivity increases with greater species richness, apparently the result of niche complementarity and positive interaction among plant species (Tilman et al. 2001). This potentially could confound the influence of plant species richness on microbial communities, because plant production (i.e., detritus) constrains microbial community biomass and function across a range of spatial and temporal scales (Zak et al. 1990, 1994). We accounted for variation in detritus production with greater plant species richness in our analyses to understand whether soil microbial communities responded to plant species richness per se or to increases in primary production associated with greater plant species richness.

\section{Methods}

\section{Experimental design and sample collection}

In 1993, an old field in the Cedar Creek Natural History Area (45 km north of Minneapolis-St. Paul, Minnesota, USA) was burned and treated with herbicide to kill the remaining plants. A portion of the surface soil was removed $(6-8 \mathrm{~cm}$ of the A horizon) to minimize the seed bank, and the site was then plowed and harrowed. In the spring of 1994, 168 plots $(9 \times 9$ m) were seeded to contain $1,2,4,8$, or 16 grasslandsavanna species (Tilman et al. 2001). Species composition was chosen by separate random draws from a pool of 18 species, which included $\mathrm{C}_{4}$ grasses, $\mathrm{C}_{3}$ grasses, legumes, forbs, and trees. The species pools consisted of: Andropogon gerardi, Agropyron smithii, Amorpha canescens, Astragalus canadensis, Buchloe dactyloides, Elymus canadensis, Koeleria cristata, Lespedeza capitata, Lupinus perennis, Panicum virgatum, Schizachyrium scoparium, Poa pratensis, Sorghastrum nutans, Petalostemum purpureum, Sporobolus cryptandrus, Monarda fistulosa, Quercus ellipsoidalis, and Quercus macrocarpa. All species grown in the multiple-species treatments also are grown individually in the 1-species treatment.

Each plot was planted with a total of $10 \mathrm{~g} \mathrm{seed} / \mathrm{m}^{2}$ in 1994 and $5 \mathrm{~g} \mathrm{seed} / \mathrm{m}^{2}$ in 1995; equal masses of each species composed a specific treatment. Treatments were maintained by frequent weeding, in which the removal of small invading plants resulted in minimal soil disruption. In July 2000, we sampled 116 of these 168 plots, which provided the following levels of replication: $n=39$ for the 1 -species treatment; $n=24$ for the 2-species treatment; $n=12$ for the 4-species treatment; $n=12$ for the 8-species treatment; $n=29$ for the 16-species treatment. Within each plot, we collected soil cores $(2.5 \mathrm{~cm}$ diameter and $20 \mathrm{~cm}$ deep) from eight random locations to characterize microbial community composition and function. The eight samples were composited and placed on ice, and all microbial analyses were initiated within $24 \mathrm{~h}$ of field collection. Soils beneath our experimental plant communities did not differ significantly in $\mathrm{C}$ or $\mathrm{N}$ concentration, but soil $\mathrm{C}$ : $\mathrm{N}$ was somewhat higher in the 16-species treatment compared to the others (Table 1).

In August 2000, plant total biomass (in grams per square meter) was measured in plots used for our analyses of microbial community composition and function (Tilman et al. 2001). Aboveground plant biomass was sampled by clipping, drying, and weighing eight 0.1 $\times 3.0 \mathrm{~m}$ strips in each plot. Belowground plant biomass was estimated by removing roots from three soil cores (5 $\mathrm{cm}$ diameter $\times 30 \mathrm{~cm}$ deep) randomly located in each clipped strip (24 cores per plot). Roots were 
washed, removed from soil by hand, dried, and weighed. Total plant biomass was calculated as the sum of above- and belowground plant tissues obtained from the destructive harvest; we used this value to estimate productivity, a portion of which annually enters soil as detritus. Subsamples of above- and belowground plant tissues were ground and analyzed for total $\mathrm{N}$ using a CE Elantech NC 1500 (CE Elantech, Lakewood, New Jersey, USA).

\section{Microbial community composition}

We used phospholipid fatty acid (PLFA) analysis to gain insight into microbial community composition beneath the experimental plant communities. Freezedried soil from each plot was extracted with a singlephase, phosphate-buffered $\mathrm{CHCl}_{3}-\mathrm{CH}_{3} \mathrm{OH}$ solvent (Bligh and Dwyer 1959) The extracted lipids were then separated into functional classes using silicic acid column chromotography (Gehron and White 1983). The polar lipid fraction was transesterified into fatty acid methyl esters (FAMEs) using a mild-alkaline system containing methanol (White et al. 1979). The resulting FAMEs were separated and identified using an Agilent 6890 GC interfaced to an Agilent 5973 mass selective detector (Agilent, Schaumburg, Illinois, USA); see Ringelberg et al. (1994). We used the mole percentage of each PLFA to indicate the relative abundance of bacteria, actinomycetes, and fungi in soil. We also used total PLFA extracted from soil as an index of living microbial biomass (White et al. 1979). Our procedure allowed us to isolate and identify 50 individual PLFAs, which composed $40.0 \pm 2.40 \%$ (mean $\pm 1 \mathrm{SE}$ ) of the total PLFA extracted from the soil.

\section{Microbial community function}

Microbial respiration, gross $\mathrm{N}$ mineralization, and gross $\mathrm{N}$ immobilization are processes that control ecosystem-level patterns of $\mathrm{C}$ and $\mathrm{N}$ cycling, and we measured them to assess change in ecosystem function with greater plant diversity. A 60-g subsample of field-fresh soil collected in each plot was placed in a $968-\mathrm{mL}$ glass jar fitted with an airtight lid containing a septum for gas sampling. After two days of incubation at $25^{\circ} \mathrm{C}$, the $\mathrm{CO}_{2}$ concentration was measured using gas chromatography (Zak et al. 1999); we calculated microbial respiration as the increase in $\mathrm{CO}_{2}$ over the two-day incubation. Two additional 20 -g subsamples from each plot were used to determine gross rates of $\mathrm{N}$ mineralization and the microbial immobilization of $\mathrm{NH}_{4}{ }^{+}$and $\mathrm{NO}_{3}{ }^{-}$. The extractable $\mathrm{NH}_{4}{ }^{+}$pool of one sample was enriched to 0.6 atom percent excess ${ }^{15} \mathrm{~N}$ with $1.0 \mathrm{~mL}$ of an aqueous ${ }^{15} \mathrm{NH}_{4} \mathrm{Cl}$ solution. The extractable $\mathrm{NO}_{3}{ }^{-}$ pool of the second sample was enriched to 0.6 atom percent excess ${ }^{15} \mathrm{~N}$ with $\mathrm{K}^{15} \mathrm{NO}_{3}$. The ${ }^{15} \mathrm{~N}$ abundance in soil pools was quantified with a Finnigan Delta Plus isotope ratio mass spectrometer with a Conflo II interface (Finnigan, San Jose, California, USA). We calculated rates of gross $\mathrm{N}$ mineralization and gross im- mobilization using isotope pool dilution equations (Hart et al. 1994). Recovery of added isotope averaged $83.4 \pm 2.15 \%$ in ${ }^{15} \mathrm{NH}_{4}{ }^{+}$amended soil, and recovery averaged $81.6 \pm 2.40 \%$ in samples that received ${ }^{15} \mathrm{NO}_{3}{ }^{-}$.

\section{Statistical analyses}

We used a one-way ANOVA to determine the influence of plant diversity on microbial community biomass (total PLFA), composition (bacterial, actinomycetal, and fungal PLFAs), and function (respiration, gross $\mathrm{N}$ mineralization and immobilization). We then added plant biomass as a covariate and used ANCOVA to determine the influence of both plant diversity and biomass on the aforementioned variables. Type III sums of squares (ss) were used to calculate an $F$ value and to determine the significance of plant diversity and biomass on each measure of microbial community biomass, composition, and function. Relationships between plant diversity and the aforementioned attributes of the soil microbial community were explored using nonlinear regression. We used treatment means $(n=$ 5) of microbial community biomass, respiration, and rates of gross mineralization and immobilization in our regression analyses, which provided a more conservative assessment of significance than using data from all plots $(n=116)$. Our level of replication in the 1 species treatment enabled us to determine whether the occurrence of a particular plant species significantly affected rates of microbial processes in the soil, and we used a one-way ANOVA to make comparisons among the individual species growing in our experiment.

\section{Results AND Discussion}

Plant diversity increased the biomass and modified the composition of soil microbial communities, but this effect was largely attributable to the increases in plant production that occurred with greater species diversity (Figs. 1 and 2). Total PLFA, an estimate of microbial community biomass, significantly increased with plant diversity and was significantly greater in the 8- and 16species treatments compared to the lower levels of species richness (ANOVA; $F=5.16$, df $=4,111 ; P<$ $0.001)$. This increase was described by a saturating exponential function, which accounted for $98 \%$ of the variation in mean microbial biomass among our experimental diversity treatments (Fig. 1A). Nonetheless, the effect of plant diversity on microbial biomass became nonsignificant (ANCOVA; Type III ss; $F=1.09$, df $=1,110 ; P=0.365)$ when we included plant biomass as a covariate (ANCOVA; $F=23.13$, df $=1$, 110; $P<0.0001$; Fig. 1B). Moreover, treatment means of total PLFA adjusted for variation in plant biomass showed no relationship with plant species richness (Fig. 1B), suggesting that plant diversity impacted microbial biomass mainly via increases in plant production. 

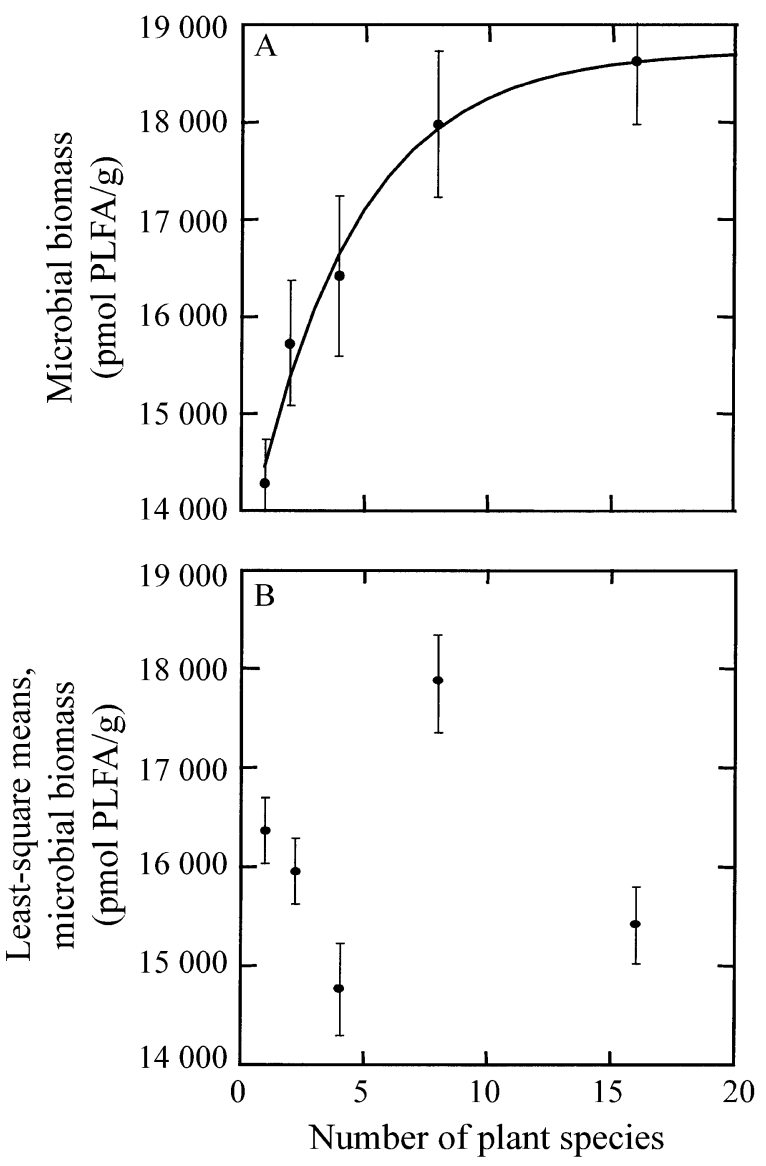

FIG. 1. Relationship of plant species richness with (A) mean microbial community biomass and (B) least-square means of microbial biomass adjusted for variation in plant biomass. The equation describing the best-fit line through treatment means in panel (A) is: pmol PLFA/g $=5433.4 \times$ $\left(1-e^{-0.239 \text { species }}\right)+13182.4\left(n=5, R^{2}=0.983, P<0.001\right)$; where PLFA is phospholipid fatty acid. There was no significant relationship between the least-square means of microbial biomass and plant species richness. Error bars indicate $\pm 1 \mathrm{SE}$.

Microbial community composition changed with greater plant diversity, an effect that also appears more attributable to increases in plant production than to greater species richness. This change is illustrated by a significant decline in PLFAs indicative of soil bacteria and actinomycetes, and an increase in those that are biomarkers for soil fungi (Fig. 2). In a one-way ANOVA, the 1-species treatment differed significantly from the 16-species treatment $(P<0.001-0.053)$ for each PLFA illustrated in Fig. 2. However, when we included plant biomass as a covariate in our analyses, plant diversity again became nonsignificant $(P=$ $0.137-0.980)$. We also observed no relationship between plant diversity and the abundance of microbial groups when individual PLFAs were adjusted for variation in plant biomass (Fig. 2). Our analysis suggests that higher levels of plant production associated with greater plant diversity fostered a shift in microbial community composition.

Plant diversity significantly enhanced rates of microbial processes that mediate ecosystem $\mathrm{C}$ and $\mathrm{N}$ cycling, but again, this effect was more strongly dependent on plant production than on species richness. During organic matter decomposition, microbial respiration returns photosynthetically fixed $\mathrm{C}$ to the atmosphere, and this microbial process increased significantly with plant diversity (ANOVA; $F=11.68$, df $=4,111 ; P<0.001)$; mean rates in the 8 - and 16 species treatments were significantly greater than rates in the other treatments. However, the saturating exponential relationship between microbial respiration and plant diversity (Fig. 3A) can be attributed to the observed increases in plant production (i.e., detritus) with greater diversity. Plant biomass was significant in our ANCOVA $(F=47.49$, df $=4,111 ; P<0.001)$, and when mean rates of microbial respiration were adjusted for differences in plant biomass, we observed no relationship between plant diversity and microbial respiration (Fig. 3B).

Rates of specific respiration, which account for differences in microbial biomass among treatments (i.e., $\mathrm{CO}_{2}$ produced per unit of microbial biomass), demonstrated that plant diversity significantly and predictably increased the metabolic activity of soil microbial communities (Fig. 3C). Nonetheless, this response also appears more attributable to increases in plant biomass than to greater plant diversity per se. Mean specific respiration differed among diversity treatments (ANOVA; $F=2.12$, df $=4,111 ; P=0.083$ ), with the 4and 16-species treatments exhibiting significantly higher rates than the 2 -species treatment. The overall increase in specific respiration was well described by a saturating exponential equation, which accounted for $59 \%$ of the variation in this process among diversity treatments (Fig. 3C). Nevertheless, plant biomass was highly significant in our ANCOVA (Type II ss; $F=$ 6.16 , $\mathrm{df}=4,111 ; P=0.014)$, whereas plant diversity was not (Type III ss; $F=1.03$, df $=4,111 ; P=$ 0.395). Again, when we adjusted rates of specific respiration for variation in plant biomass among treatments, we found no relationship between plant diversity and specific microbial respiration (Fig. 3D). Although previous evidence suggests that plant diversity can have an inconsistent effect on plant litter decomposition (Wardle et al. 1997), the consistently greater rates of microbial metabolism that we observed in the most species-rich experimental communities (Figs. 3A and 4A) should hasten organic matter decomposition, making $\mathrm{N}$ more available for plant growth.

Plant productivity in old fields and prairies surrounding our experiment is limited by soil N (Tilman 1987), the supply of which is controlled by the balance between microbial mineralization (i.e., release) and immobilization (i.e., assimilation). Gross $\mathrm{N}$ mineralization nearly doubled from the 1 - to 16 -species treatments 


\section{$\square$ Bacteria $\square$ Actinomycetes $\square$ Fungi}
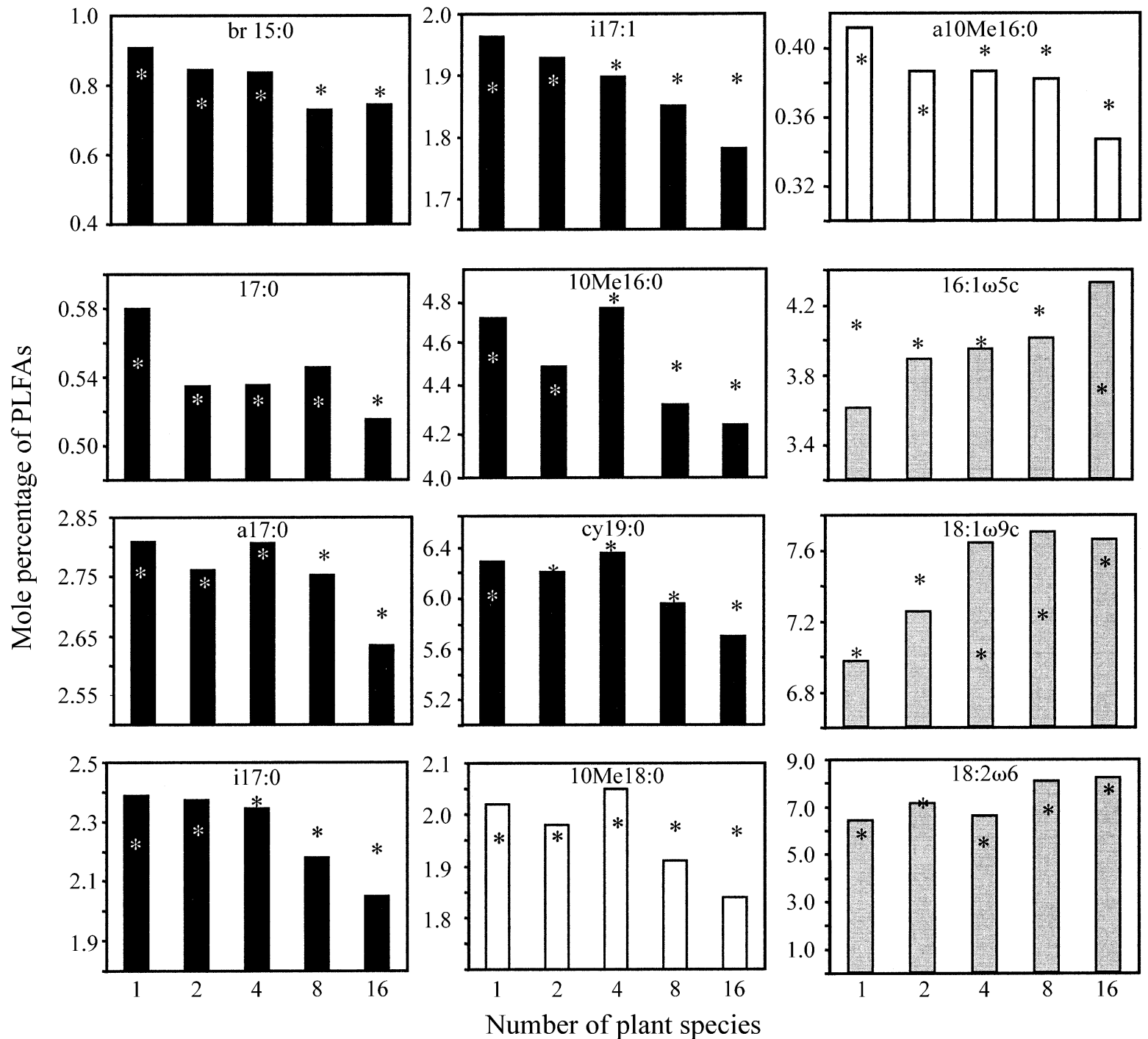

FIG. 2. Bacterial, actinomycetal, and fungal phospholipid fatty acids (PLFAs) that differed significantly among plant diversity treatments with $1,2,4,8$, or 16 species. Least-square means (values indicated by positions of asterisks [*]) adjusted for variation in plant biomass indicate no relationship with plant species richness. Individual compounds are given at the top of each panel in standard lipid notation.

(ANOVA; $F=10.6, \mathrm{df}=4,111 ; P<0.001)$ and displayed a predictable increase across the range of diversity in our experiment (Fig. 4A). This relationship occurred even when we adjusted rates of gross $\mathrm{N}$ mineralization for differences in plant biomass and soil organic matter among treatments, indicating that plant diversity enhanced the microbial release of $\mathrm{NH}_{4}{ }^{+}$from soil organic matter (Fig. 4B and C). In contrast, plant diversity had no effect on the microbial assimilation of $\mathrm{NH}_{4}{ }^{+}$(ANOVA; $F=0.67, \mathrm{df}=4,115 ; P=0.614$ ) or $\mathrm{NO}_{3}{ }^{-}($ANOVA; $F=0.85, \mathrm{df}=4,115 ; P=0.497)$, and there was no relationship between plant diversity and these microbial processes (Fig. 5). Plant biomass was a significant covariate in our analysis of $\mathrm{NH}_{4}^{+}$ immobilization $(F=9.76, \mathrm{df}=4,111 ; P=0.002)$, but there was no significant relationship between the least-square means of $\mathrm{NH}_{4}{ }^{+}$immobilization and plant diversity (data not shown); plant biomass was not a significant covariate of $\mathrm{NO}_{3}{ }^{-}$immobilization $(F=$ $1.88 ; P=0.174)$.

In our experiment, the balance between gross $\mathrm{N}$ mineralization and immobilization was altered by plant diversity such that the net supply of soil $\mathrm{N}$ increased with the number of plant species present. This greater $\mathrm{N}$ 

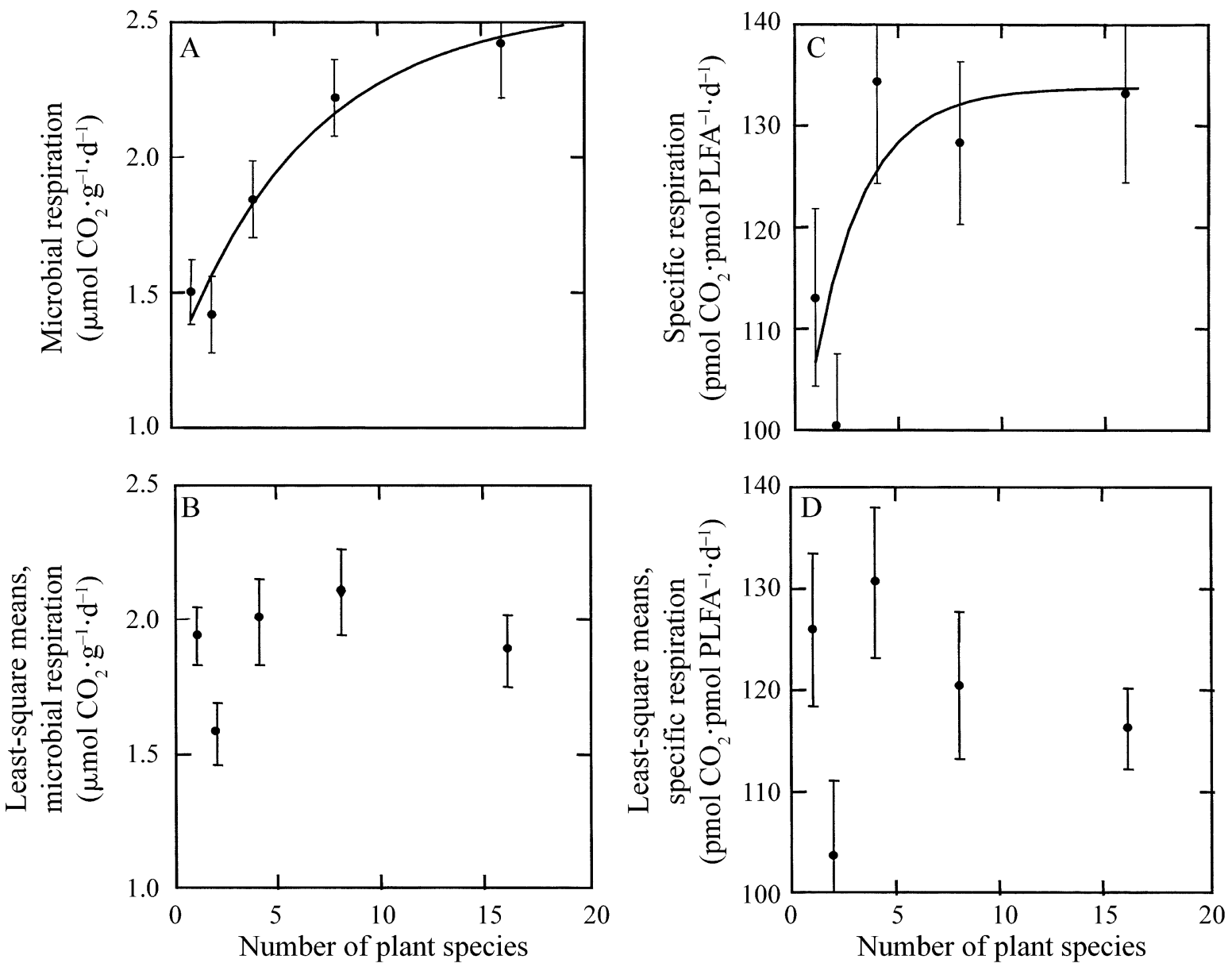

FIG. 3. Relationship of plant species diversity with (A) microbial respiration and (B) least-square means of microbial respiration, (C) specific microbial respiration, and (D) least-square means of specific microbial respiration. The best-fit line through treatment means of microbial respiration was $\mu \mathrm{mol} \mathrm{CO} \cdot \mathrm{g}^{-1} \cdot \mathrm{d}^{-1}=1.35\left(1-e^{-0.153 \text { species }}\right)+1.22\left(n=5, R^{2}=0.953\right.$, $P<0.001)$. The change in mean specific respiration with plant diversity (C) was described by the following equation: pmol $\mathrm{CO}_{2} \cdot \mathrm{pmol} \mathrm{PLFA}^{-1} \cdot \mathrm{d}^{-1}=37.55\left(1-e^{-0.329 \text { species }}\right)+96.20\left(n=5, R^{2}=0.591, P<0.001\right)$. There was no significant relationship between plant species richness and the least-square means of microbial respiration or specific microbial respiration. Error bars indicate $\pm 1 \mathrm{SE}$.

supply undoubtedly contributes to the positive relationship between plant diversity and productivity in the N-limited soil of our experiment (Tilman et al. 1997, 2001) and, in part, probably accounts for a significant increase in total plant $\mathrm{N}$ content with greater diversity (Fig. 6). We observed that total plant $\mathrm{N}$ content increased significantly from the 1 - to 16 -species treatments $(F=25.10$, df $=4,111 ; P<0.001)$, which is consistent with the general increase in gross $\mathrm{N}$ mineralization that we observed across our diversity treatments. Niche complementarity and the greater microbial supply of growth-limiting soil $\mathrm{N}$ are likely to be mechanisms that fostered higher levels of plant productivity in the most species-rich experimental communities.

One might argue that it was the presence of a particular plant species or functional group that was responsible for altering microbial community function; we have no evidence to suggest that this was the case in our experiment. Using two-way ANOVAs containing species richness and functional group presence (e.g., species richness and legume presence/absence, etc.), we found no evidence that the occurrence of legumes, $\mathrm{C}_{3}$ grasses, $\mathrm{C}_{4}$ grasses, non-legume forbs, or trees in our diversity treatments influenced the rates of gross $\mathrm{N}$ mineralization $(P=0.566-0.783)$; our analysis was identical for microbial respiration, specific respiration, and microbial immobilization. Moreover, we also compared attributes of the microbial community among the monocultures (i.e., 1-species treatment) of the 18 species composing our diversity treatments, and we observed no effect of plant species on microbial community biomass (ANOVA; $F=0.65 ; P=0.812$ ), respiration $(F=0.81 ; P=0.669)$, specific respiration $(F$ $=0.57 ; P=0.884)$, gross $\mathrm{N}$ mineralization $(F=1.90$; $P=0.086)$, and microbial immobilization of $\mathrm{NH}_{4}{ }^{+}(F$ 

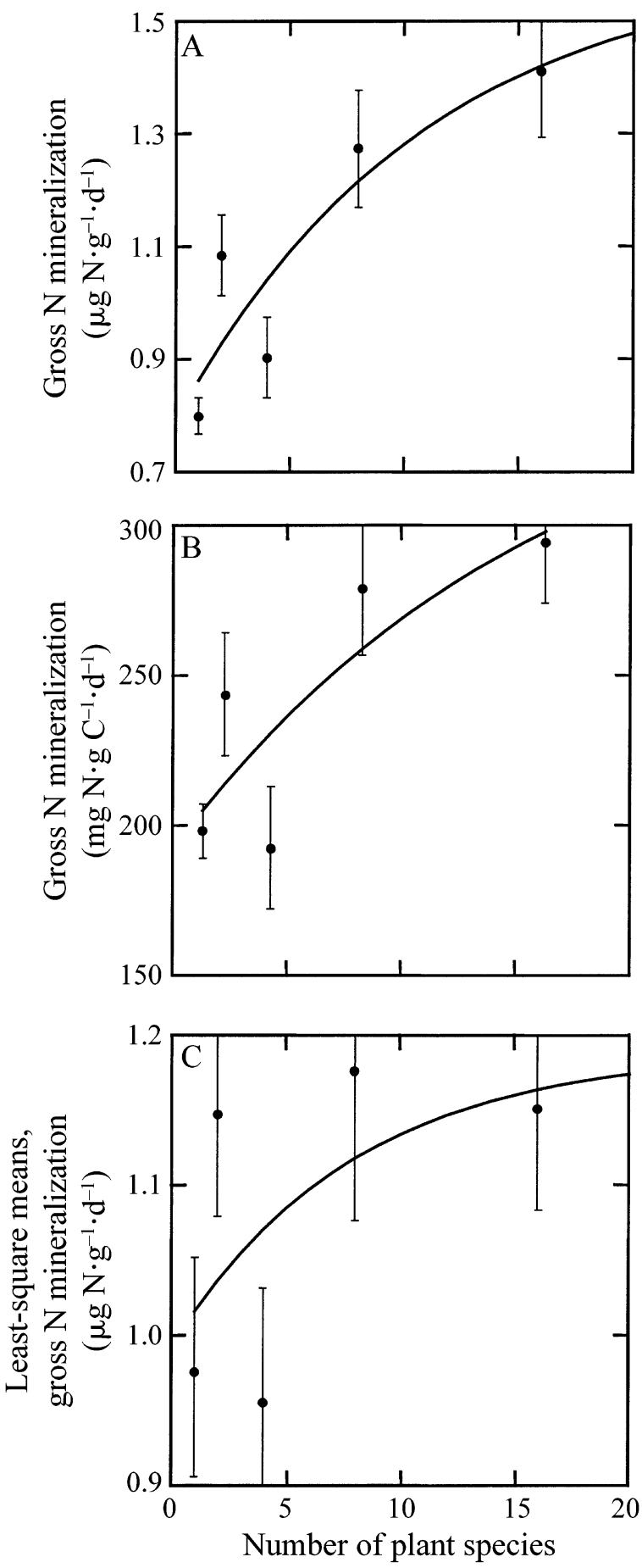

FIG. 4. Relationship of plant species diversity with mean rates of gross $\mathrm{N}$ mineralization. Rates were expressed (A) per unit of soil $\left(\mu \mathrm{g} \mathrm{N} \cdot \mathrm{g}^{-1} \cdot \mathrm{d}^{-1}=0.821\left(1-e^{-0.091 \text { species }}\right)+0.790\right.$; $\left.n=5, R^{2}=0.799, P<0.001\right)$ and (B) per unit of soil organic matter $\left(\mu \mathrm{g} \mathrm{N} \cdot \mathrm{g} \mathrm{C}^{-1} \cdot \mathrm{d}^{-1}=163.9\left(1-e^{-0.061 \text { species }}\right)+195.1 ; n\right.$ $\left.=5, R^{2}=0.668, P<0.001\right)$. The relationship between leastsquare means adjusted for plant biomass and species richness (C) was highly significant $\left(\mu \mathrm{g} \mathrm{N} \cdot \mathrm{g}^{-1} \cdot \mathrm{d}^{-1}=0.197\left(1-e^{-0.126}\right.\right.$ species) $+0.996 ; n=5, R^{2}=0.320, P<0.001$ ), but species richness accounted for a smaller proportion of the variation among treatments.
$=1.14 ; P=0.390)$ or $\mathrm{NO}_{3}^{-}(F=0.79 ; P=0.652)$. Thus, we cannot attribute changes in microbial community composition and function to the occurrence of a particular plant functional group, nor can we attribute these changes to the presence of a particular plant species.

An increase in plant biomass across our diversity treatments suggests that plants in the most species-rich experimental communities might use greater amounts of soil water than those at the lower levels of diversity. Such a response would reduce soil matric potential as plant diversity increased, which could alter microbial community composition and function by favoring fungal dominance (Fig. 2; Paul and Clark 1996). We compared soil matric potential among diversity treatments in July 1998, 1999, and 2000, because it is the month during which soil water attains the greatest deficit (Greenland 1987). Soil matric potential did not differ
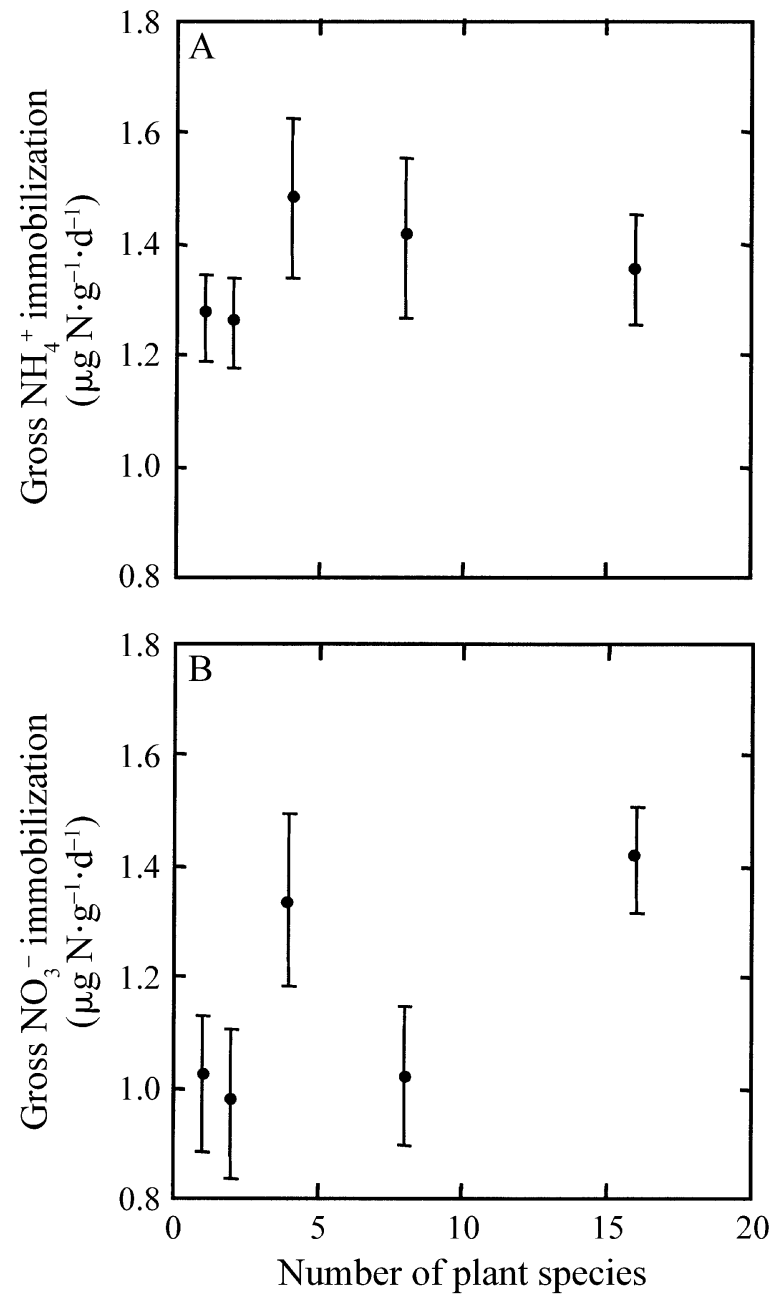

FIG. 5. The relationship between plant species richness and the microbial immobilization of (A) $\mathrm{NH}_{4}{ }^{+}$and (B) $\mathrm{NO}_{3}{ }^{-}$. We found no relationship between these microbial processes and the level of plant species richness. Error bars indicate \pm 1 SE. 


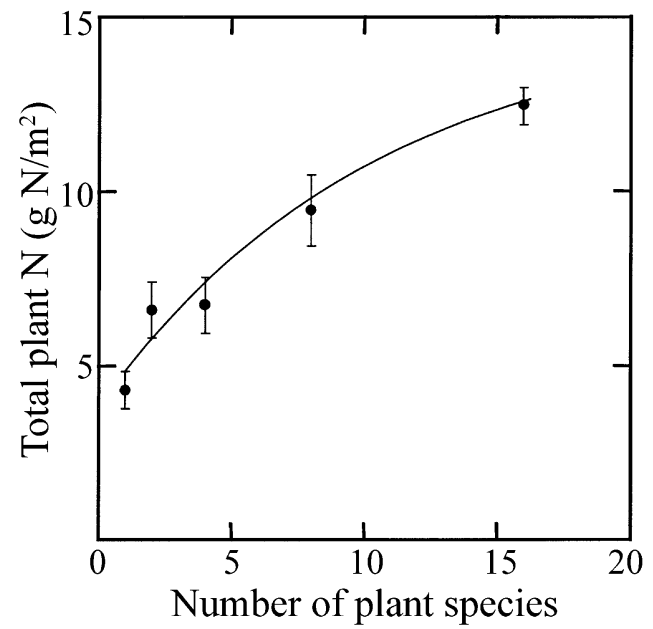

FIG. 6. The relationship between the amount of $\mathrm{N}$ contained in plant biomass and species richness. The amount of $\mathrm{N}$ contained in above- plus belowground plant biomass averaged $4.29+0.456 \mathrm{~g} \mathrm{~N} / \mathrm{m}^{2}$ in the one-species treatment, and this value increases significantly to $12.5+0.493 \mathrm{~g} \mathrm{~N} / \mathrm{m}^{2}$ in the 16-species treatment (ANOVA, $F=25.10$, df $=4,115$, $P<0.001)$. This relationship was described by the following equation: $\mathrm{g} \mathrm{N} / \mathrm{m}^{2}=12.07\left(1-e^{-0.077 \text { species }}\right)+3.954 ; n=5$, $R^{2}=0.967, P<0.001$. Error bars indicate $\pm 1 \mathrm{SE}$.

among diversity treatments in $1998(P=0.300)$ or $2000(P=0.132)$. However, significant differences occurred in 1999, with the 16-species treatment having a greater matric potential (i.e., more soil water; -0.013 $\pm 0.000 \mathrm{MPa})$ than the other treatments $(-0.014$ to $-0.019 \mathrm{MPa})$. It also is conceivable that plant-induced changes in soil $\mathrm{pH}$ could modify microbial communities in our experiment. Although soil $\mathrm{pH}$ was significantly greater in the 16-species treatment (6.36) compared to values in the other treatments $(6.02-6.18 ; P$ $=0.005)$, this difference was small (Table 1). These data support the idea that plant diversity, rather than plant-mediated changes in the soil environment across diversity treatments, influenced soil microbial communities.

Our results demonstrate that plant diversity impacted ecosystem processes by modifying the composition and function of heterotrophic microbial communities in soil. Many of the responses that we observed could be explained by greater plant production (i.e., detritus production) associated with higher levels plant diversity, which are likely to result from niche complementarity, positive interactions, and greater resource capture in the most species-rich experimental plant communities (Tilman et al. 2001). This appears to have fostered greater rates of microbial respiration at higher levels of plant diversity, but not when this process was normalized for differences in plant production. The pattern of gross $\mathrm{N}$ mineralization roughly matched the increase in microbial respiration, suggesting that greater microbial activity is one mechanism behind the increase in $\mathrm{N}$ mineralization. However, when $\mathrm{N}$ mineralization was adjusted for differences in plant production, there was still a significant relationship with plant diversity, indicating that greater rates of decomposition were not the only mechanism at work.

Although the exact mechanisms causing greater rates of $\mathrm{N}$ mineralization remains to be determined, plant diversity altered microbial community composition and function, which, in turn, increased the supply of soil $\mathrm{N}$ to plants and contributed to greater productivity in the most species-rich experimental plant communities. This feedback is likely to be most evident in ecosystems where existing substrate pools in soil (i.e., organic matter) are small relative to amounts entering soil from plant detritus. For example, soil in our experiment contained very little organic matter $(4-5 \mathrm{~g} \mathrm{C} / \mathrm{kg}$ ) relative to another experiment $(130 \mathrm{~g} \mathrm{C} / \mathrm{kg})$ in which plant diversity did not influence soil microbial communities and litter decomposition (Wardle et al. 1999). Our results imply that the loss of plant species may have the greatest impact on microbial communities in ecosystems containing infertile soils poor in organic matter. They also demonstrate that the response of soil microbial communities can be an integral component of plant diversity's influence on ecosystem function. Feedbacks between plant and microbial communities control ecosystem productivity, and our results demonstrate that plant species richness is an important factor influencing this biotic interaction.

\section{ACKNOWLEDGMENTS}

Our work was supported by grants from the National Science Foundation, Department of Energy's Office of Biological and Environmental Research (BER), and the USDA Forest Service. Matthew Tomlinson provided assistance in the field and Rebecca Phillips contributed to our PLFA analyses; we thank them both.

\section{Literature Cited}

Bargett, R. D., and A. Shine. 1999. Linkages between plant litter diversity, soil microbial biomass and ecosystem function in temperate grasslands. Soil Biology and Biochemistry 31:317-321.

Bligh, E. G., and W. J. Dwyer. 1959. A rapid method of total lipid extraction and purification. Canadian Journal of Biochemistry and Physiology 37:911-917.

Caldeira, M. C., R. J. Ryel, J. H. Lawton, and J. S. Periera. 2001. Mechanisms of positive biodiversity-production relationships: insights provided by $\delta^{13} \mathrm{C}$ analysis in experimental Mediterranean grassland plots. Ecology Letters 4: 439-443.

Gehron, M. J., and D. C. White. 1983. Sensitive assay of phospholipid glycerol in environmental samples. Journal of Microbiological Methods 1:23-32.

Greenland, D. 1987. The climates of the long-term ecological research sites, Occasional Paper Number 44, Institute of Arctic and Alpine Research, University of Colorado, Boulder, Colorado, USA.

Hart, S. C., J. M. Stark, E. A. Davidson, and M. K. Firestone. 1994. Nitrogen mineralization, immobilization, and nitrification. Pages 985-1018 in R. W. Weaver, S. Angel, P. Bettomley, D. Bezdicek, S. Smith, A. Tabatabai, and A. Wollum, editors. Methods of Soil Analysis. Part 2: Microbiological and biochemical properties. Soil Science Society of America, Madison, Wisconsin, USA. 
Hector, A., et al. 1999. Plant diversity and productivity experiments in European grasslands. Science 286:1123-1127.

Hooper, D. U., and P. M. Vitousek. 1998. Effects of plant composition and diversity on nutrient cycling. Ecological Monographs 68:121-149.

Huston, M. A. 1997. Hidden treatments in ecological experiments: re-evaluating the ecosystem function of biodiversity. Oecologia 110:449-460.

Loreau, M. 2001. Microbial diversity, producer-decomposer interactions and ecosystem processes: a theoretical model. Proceedings of the Royal Society of London B 268:303309.

Loreau, M., and A. Hector. 2001. Partitioning selection and complementarity in biodiversity experiments. Nature 412: 72-76.

Loreau, M., S. Naeem, P. Inchausti, J. Bengtsson, J. P. Grime, A. Hector, D. U. Hooper, M. A. Huston, D. Raffaelli, B. Schmid, D. Tilman, and D. A. Wardle. 2001. Biodiversity and ecosystem functioning: current knowledge and future challenges. Science 294:804-808.

May, R. M., J. H. Lawton, and N. E. Stork. 1995. Assessing extinction rates. Pages 1-24 in J. H. Lawton and R. M. May, editors. Extinction rates. Oxford University Press, Oxford, UK.

Paul, E. A., and F. E. Clark. 1996. Soil microbiology and biochemistry. Third edition. Academic Press, New York, New York, USA.

Pimm, S. L., G. J. Russell, J. L. Gittleman, and T. M. Brooks. 1995. The future of biodiversity. Science 269:347-350.

Ringelberg, D., G. T. Townsend, K. A. Deweerd, J. M. Suflita, and D. C. White. 1994. Detection of the anaerobic dechlorinating microorganism Desulfomonile tiedjei in environmental matrices by its signature lipopolysaccharide branched-long-chain hydroxy fatty acids. FEMS (Federation of European Microbiological Societies) Microbial Ecology 14:9-18.

Smith, J. L., and E. A. Paul. 1990. The significance of soil microbial biomass estimations. Pages 357-396 in J. Bollag and G. Stotsky, editors. Soil biochemistry. Marcel Dekker, New York, New York, USA.

Stephan, A., A. H. Meyer, and B. Schmid. 2000. Plant diversity affects culturable soil bacteria in experimental grassland communities. Journal of Ecology 88:988-999.
Tilman, D. 1982. Resource competition and community structure. Princeton University Press, Princeton, New Jersey, USA.

Tilman, D. 1987. Secondary succession and the pattern of plant dominance along experimental nitrogen gradients. Ecological Monographs 57:189-214.

Tilman, D., J. Knops, D. A. Wedin, P. Reich, M. Riche, and E. Seaman. 1997. The influence of functional diversity and composition on ecosystem processes. Science 227:13001302.

Tilman, D., P. Reich, J. Knops, D. Wedin, T. Mielke, and C. Lehman. 2001. Diversity and productivity in a long-term grassland experiment. Science 294:843-845.

Tilman, D., D. A. Wedin, and J. Knops. 1996. Productivity and sustainability influenced by biodiversity in grassland ecosystems. Nature 379:718-720.

Wardle, D. A., K. I. Bonner, G. M. Barker, G. W. Yeates, K. S. Nicholson, R. D. Bardgett, R. N. Watson, and A. Ghani. 1999. Plant removals in perennial grassland: vegetation dynamics, decomposers, soil biodiversity, and ecosystem properties. Ecological Monographs 69:535-568.

Wardle, D. A., K. I. Bonner, and K. S. Nicholson. 1997. Biodiversity and plant litter: experimental evidence which does not support the view that enhanced species richness improves ecosystem function. Oikos 79:247-258.

White, D. C., W. M. Davis, J. S. Nickels, J. D. King, and R. J. Bobbie. 1979. Determination of the sedimentary microbial biomass by extractable lipid phosphate. Oecologia 40: 51-62.

Zak, D. R., D. F. Grigal, S. Gleeson, and D. Tilman. 1990. Carbon and nitrogen cycling during secondary succession: constraints on plant and microbial biomass. Biogeochemistry 11:111-129.

Zak, D. R., W. E. Holmes, N. W. MacDonald, and K. S. Pregitzer. 1999. Temperature, matric potential, and the kinetics of microbial respiration and net $\mathrm{N}$ mineralization in northern hardwood forests. Soil Science Society America Journal 63:575-584.

Zak, D. R., D. Tilman, R. R. Parmenter, C. W. Rice, F. M. Fisher, J. Vose, D. Milchunas, and C. W. Martin. 1994. Plant production and soil microorganisms in late-successional ecosystems: a continental-scale study. Ecology $\mathbf{7 5}$ : 2333-2347. 